\title{
Just-in-time Teaching, Just-in-need Learning: Designing towards Optimized Pedagogical Outcomes
}

\author{
Steinar Killi", Andrew Morrison \\ Institute of Design, Centre of Design Research, Oslo School of Architecture and Design, Norway
}

Copyright (C) 2015 by authors, all rights reserved. Authors agree that this article remains permanently open access under the terms of the Creative Commons Attribution License 4.0 International License

\begin{abstract}
Teaching methods are constantly being changed, new ones are developed and old methods have undergone a renaissance. Two main approaches to teaching prevail: a) lecture-based and project-based and b) an argumentative approach to known knowledge or learning by exploration. Today, there is a balance between these two approaches, and they are more complimentary than opposites. However, the development of new tools, such as additive manufacturing (3D printing), and shifts in the way knowledge is obtained and consumed has led to emerging new methods to teaching and learning. This paper will address two of the new trends in the concepts and related practices of Just-in-time teaching and Just-in-need learning in the context of design education. Over the past fifteen years, these approaches have been developed, tested and implemented in the five-year master's program in design at the Oslo School of Architecture and Design. In summary, we have found that in project-based learning, different ways of teaching methods should be timed with the different types of student motivation. However, we argue that our findings are relevant for education on all levels. The key to understanding these two concepts and related practices is to know when the timing for input is optimal. To be motivated to solve something does not necessarily mean you are motivated to learn something. Further, it is important that the chosen learning outcome is actually achieved. Equally, knowing when scarce resources should be used is of no less importance. We conclude in suggesting that designing teaching inputs could enhance the learning outcomes and better use resources at hand. Further, in this way, planned learning outcomes could be tracked, both in reference to explicit and tacit knowledge. We coin the term Apposite Pedagogic Action as one way of to addressing this dynamic.
\end{abstract}

Keywords Just-in-time, Just-in-need, Tacit Knowledge, Intrinsic and Extrinsic Motivation, Design Education, PBL, Apposite Pedagogic Action

\section{Introduction}

\section{Focus of the Inquiry}

In this article we address the changing needs and character of higher education pedagogies in design that are suited to context, needs and task. Our focus is on design pedagogies that are concerned to support students' moves from novices to experts in a wider sociocultural framing of design education[1]. This is an approach that investigates the dialogical intersections and shared meaning making between learners and educators, and the tools and meditational technologies they negotiate[2 3] in a developmental approach to learning. Here what are important are the motivations, activities and analyses of practice-based inquiry in relations between the mediational as artifacts and tools, as skills and articulations, and cultural and contextual situations for learning. Importantly, little work has been done in this frame within design schools or in acknowledgment of design educators own pedagogical expertise and praxis.

The substance and findings presented in this article are based on experiences from design-centered teaching and learning from a total of 21 years at the Oslo School of Architecture and Design (AHO). This school has had Project Based Learning (PBL) as the main pedagogical method since it was founded in 1945. PBL is an approach in the learning sciences with related pedagogy that emphasizes motivation[4].

In the context of pedagogy for product design, we pose a number of research questions. How might we better understand relations between the contexts of design studio based inquiry and the role of student-centered inquiry based learning and inputs from educators in the form of both dialogical inputs and lectures? In what ways might we anticipate what and when to provide explicit input concerning different types of motivation in the creative activities of design students? What aspects of the design process may be understood developmentally and be related to pedagogical strategies in order to better to map when and where to do what pedagogically? 


\section{'Learning Settings'}

Over the years, lectures in history, mechanics and materials have complimented both PBL tasks and a studio-oriented context for learning. Together these developments over time have led us to frame a wider approach to design and learning in terms of an integrated pedagogy framed in a sociocultural perspective to learning [3 56 . Central here is the notion of situated cognition[7-9] .

Design education is dominated by the studio method that has over time shifted from the expressive outputs of the individual designer in an apprenticeship and crafts model to a more dynamic sense of shared processes and outcomes of learning that entail reflection in and on action[10] . Studio based pedagogy draws on the brief, may be open ended, deal with complex problems and a set of iterations and transformations concerning a diversity of issues and direction towards holistic and mediated thinking and communication[11]. The approach is connected closely to 'designerly ways of knowing'[12-14]

We have seen that the timing of teaching inputs has been crucial for students, especially where this has covered exposure to new domains, materials and tools and their intersections. Positioning and orienting lectures, not just delivering them, has been needed, as has offering ones that have delved more deeply into specific features and needs of design inquiry. We know, despite these situated cognition framings of design knowing, and the design of a process directed pedagogy, that some lectures are remembered and circulated, and some are not. What is interesting is that these lectures could be identical but just held at different times. There appears to be more to successful learning than the actual quality of teaching methods. This paper seeks out to elaborate when teaching input could be most effectively enacted, based on experiences over a diversity of student groups and courses in industrial design. Here what matters is just when it is that what types of pedagogy and access to knowledge is enacted, that is just-in-time. This extends to issues of what is needed and when and to what end, or just-in-need. The paper elaborates approaches to this by addressing models of learning in relation to motivation and designerly ways of working. We conclude by suggesting these elements be understood cumulatively and assembled under what we term A Model of Apposite Pedagogical Action.

\section{Contexts}

\subsection{On PBL}

During the past 30 years by project- and problem-based learning (PBL) has been praised as the future of education[15], with arguments that working with projects leads to much more motivated students, hence higher learning outcome. Adderley et al. (1975: p1)[16] provided a summary of PBL that is still valid. It involves the solution of a problem, though not necessarily set by the student himself/herself; it involves initiative by the student or group of students, and necessitates a variety of educational activities. The result is usually an end product (e.g., report, computer program, a model). The process often goes on for a considerable period of time. Teaching staff assume advisory rather than directive roles.

However, claims for PBL have been challenged in terms of problems in comparing research results, due to the many ways to run PBL and even that results, for instance physics tests, provided very small differences in achievements for those having followed lectures and those carrying out PBL activities[17] . In many higher educational institutions that have typically had a lecture-centred approach, we now see attempts to shift more broadly to a project-based one. Conversely, universities based on a PBL approach see the need to mix in lectures in their pedagogical philosophy (also seen in a shift from Content Management Systems (CMS) to Massive Open Online Courses (MOOCs)[18] . The lecture-based teaching method still holds its ground in many settings.

Success criteria concerning PBL are very often solely placed on the teacher/lecturer to contextualise the topic and narrate a 'story' [19]. There is rather broad consensus on key elements for successful learning[20], such as good physical environment, feelings of acceptance, ability to master the task, good dialogue etc. One major element is that of motivation[21] . Motivating for and in learning has been thoroughly investigated concerning online learning, student centred methods, issues of ownership etc[22] . In this regard a distinction has been made between problem- and project-based learning. In contrast to the former, the latter refers to longer and more open-ended projects [23] .

One angle to explore in project-based learning is to look at interest and value, two key elements in that approach [24] . Drawing on the findings of Malone and Leppers[25], Blumenfeld et al. [24] examined what factors might enhance student interest and perceived learning value. These factors were: that a) there be variety and novelty, where a learning activity should contain more than just reproducing known knowledge; b) a learning activity should be realistic and have meaning: c) there should be some kind of challenge; d) there be closure, with a natural end to the task; e) there be more than one way to solve the given task; and, f) there be included the possibility to work with others.

\subsection{From Teaching to Learning}

In "From Teaching to Learning - A New Paradigm in Higher Education" [26] Barr and Tagg discuss a sea change in the conceptualisation and implementation of learning from providing instructions to produce learning. There are several reasons for this, including a more rapidly changing society, the ability to adapt but also the pedagogical methods used, and shifts in relations between lecture and discussion[26] . These they frame within what they label The Learning Paradigm. These scholars do not anticipate the end of 
lecturing. They go on to identify one key challenge with the Learning Paradigm, namely that of incorporating knowledge transfer when and where it is necessary. Here too knowledge transfer should not be seen simply in an outdated transmission model of learning or communication.

In practice we see that learning, for instance a computer program, is strongly linked to context; following a tutorial is almost useless if it is not motivated towards solving a task. Even then, however, a tutorial typically becomes a teaching platform not a learning platform. From a student's perspective, you do not find the solutions you seek, but are overwhelmed with skills-directed knowledge that is then often deemed useless and as yet impossible to relate to developmental design and work settings. These are the wider contexts of application that lie ahead in a learning trajectory.

\subsection{Beyond Tacit Knowledge}

In contrast, an additional challenge is that, even though we all live in a fast changing society in which knowledge may be made obsolete almost before its known[27], there are still important issues concerning tacit knowledge in design. Earlier Polanyi[28] distinguished between internalised and unarticulated inner, or tacit, knowledge. This is knowledge that is characterised by being sensual and conceptual and may be discovered by acknowledging its emergence and connoisseurship. This contrasts sharply with the formalist and explicit ways of knowing in the natural sciences and methods that seek validation and replicability.

Although Nightingale[29] likened tacit knowledge to physicists "dark matter", such a view explains away the empirical failures of existing theory because we relate to non-explicit knowledge all the time. In teaching processes, repeating and training have been a core part of everyday school life. Whether this is perceived as fun or a necessary evil is very often influenced by how we facilitate learning. The use of games and other activities has therefore often been employed to make tedious exercises more enjoyable and even fun, thereby sparking intrinsic motivation. Still, in the chase to motivate the learning of new explicit knowledge, the adequate allocation of time to enable and increase tacit knowledge is essential.

\subsection{Different Types of Motivation}

As all teachers know, motivated students are probably the single most important element for successful learning to occur in a group or class. Equally, individual motivation may propel single students onwards. With curiosity and a measure of ingenuity, deep learning may occur. However, there are several types of motivation, with the two main types being intrinsic (IM) and extrinsic (EM). IM is in short inner motivation: this is when you do something because it's fun, and refers to fulfilling interesting preoccupations, directions and needs. In this form of motivation, there are no rewards or penalties in play. Alternatively, EM is basically driven by rewards and/or penalties. In the context of work, these may include salaries; in the educational system, these may be grades.

There has been lengthy discussion on the impact and importance of these two types of motivation. Whether IM is the preferred type of motivation and whether EM could actually harm IM is still debated [30]. As Lemos et al. claim, there is a strong argument for a combination of the two, as compliments to one another[31]. In PBL the pedagogical strength is very often explained by the intrinsic motivation it creates[31] . There is, however, a transition between the two types of motivation, knowing when this transition happens. What it implies from a teacher's point of view is very valuable. This will be further elaborated in section 3 , and by way of the examples given from a particular task.

\subsection{A matrix of Knowledge with Motivation}

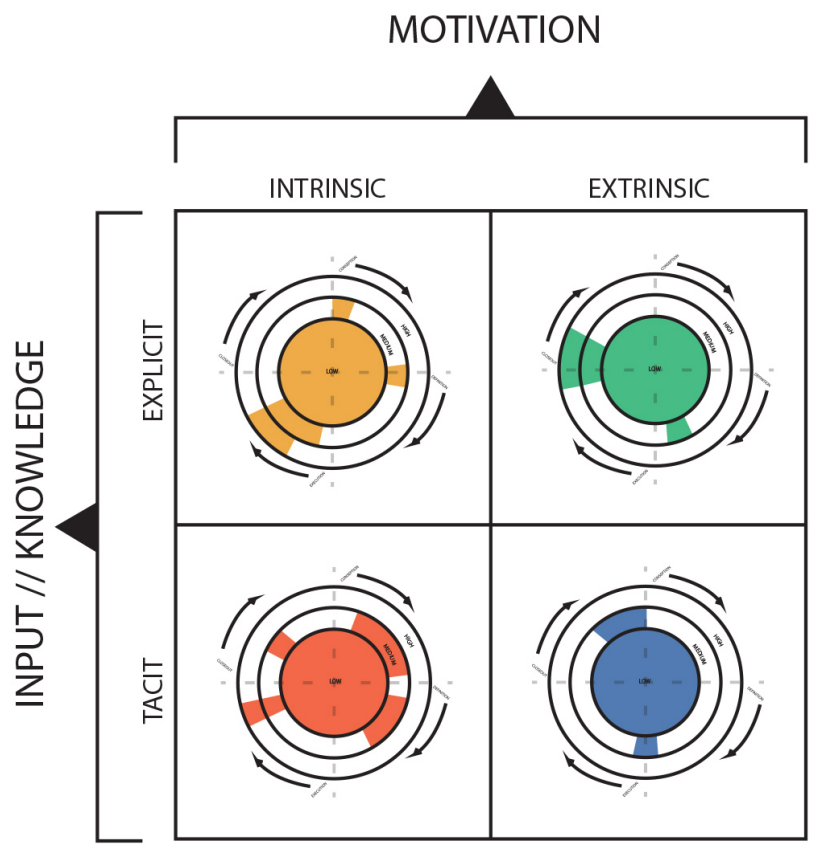

Figure 1. A matrix of knowledge with motivation. Based on the two types of motivation, intrinsic and extrinsic, in combination with the two main types of knowledge building, explicit and tacit, four types of knowledge motivations may be derived (shown by colors) (Maria Karlsen, Steinar Killi, Andrew Morrison)

Tsoukas[32] argued that explicit and tacit knowledge are not opposites along a continuum, but more like two sides of the same coin. As we will see in the example presented in section 3, students may be motivated to acquire new, explicit knowledge, but also to increase their tacit knowledge during a project. Again, awareness of when it is that this happens is of great value. Figure 1 show a tentative description of the different knowledge motivations that is typically at play in a design project, but also in any typical project. The different types of learning motivations will be exemplified in the illustrative case in section 4 below. However, the wider making and learning activities in a design studio involve a mesh of actions that need to be understood in terms of time and need. 


\subsection{Just-in-time and Just-in-need Learning}

In contrast to the usual attention given to building constructive motivation and a form of 'progressive' problem solving, frustration combined with motivation may act as a powerful agent for learning. It might be conceptualised and positioned pedagogically so as to open up for actual teaching if delivered at the correct time, or as the adage goes "just-in-time". This would need to be done not too early so that the teacher solves the problem, but also not too late with the result that a student's frustration turns into aggression or disinterest. Based on this, one could claim that even a lecture could have high pedagogical outcome if delivered at the right time, that is when the students need it. There is a window of opportunity for teaching and learning; the task is to know when it appears and exploit it. Who requests and who decides when this should be done is a matter for further investigation.

This then leads to questions concerning how the term "just-in-need" may be framed and put into practice in design pedagogy. To date, it has been used in educational research literature and pedagogy to refer to hands on projects, diversity and consisting learning targets.

\subsection{Competing and Complementary Needs}

There is a very real danger for students of design to become rather (too) quickly frustrated. This frustration may then be magnified unfruitfully, in reaction to not seeing the directions and potential uses of tools and technologies, material or processes. Their mismatch between procedural knowledge and conceptual and applied active knowing may result in disinterest or disengagement - not unalike the alienation experienced in a boring lecture. If, on the other hand, a specific task has to be solved and the tool to solve it needs to be taught, the ability to withstand frustration is almost proportional with the perception of the importance of the task. In other words, from a student's view the question becomes how motivated is one so as to be able to solve the task at hand. This is important when that task takes the form of a design brief that entails a mix of competencies over time. It also involves process of working with what may be indistinct problems and ways to finding routes to providing design solutions over time and in elation to options. These may need to be arrived at via trial and error, by the juxtaposition of options, through the exploration of alternatives and by way of studying complex decision-making across and between them.

For example, in over the past quarter century of design education we have observed how the students in the (industrial and later diversified) design department at AHO have learned and developed their Computer Aided Design (CAD) skills. From running tutorials and even teacher-led courses we have seen that the actual outcomes were often thin. However, when students were given a task to solve matters, preferably their own design, the frustration that developed when trying to figure out how to do things, led to an almost exponential positive learning curve in understanding and using the tool. Trying different ways to solve the task also meant students were touching on a number of areas that in effect did not solve their problem. Yet, they understood what the approach they arrived at could be applied in a later situation, such that they saw that they were actually adding to their wider tacit knowledge and understood the processes of their progression towards decisions and design choices and products.

\section{Methods}

\subsection{Research through Design}

This article is located within pedagogy in design that is centered on what is known as the studio based approach (see above). In terms of research methods, this approach is realized by adopting a research through design view [33 34] . Methodologically, research through design locates inquiry reflexively [35]. In processes of dynamic, iterative making and reflection, and typically uses a variety of methods from qualitative inquiry to track, capture and present these. Attention to knowledge arrived at through the activities and reflection on design practice is central[36]. In the research reported here this was also framed within the oscillation of methods of action research[37] .

\subsection{Research Methods and Design Tools}

Mixed qualitative research methods [38] were taken up and adopted over the duration of the studio and related course. These methods included participant observation on the part of the main design educator and first author of this article. Discussion and dialogue, with noted reflections were conducted as part of a design and learning based research approach to studio-centered pedagogy in design. Documentation of work in progress and final student designs was conducted by students and their main tutor, students' own projects were archived, selections of best practice projects were stored and processes of interaction, review and critical interpretation were carried out between the first and second authors of the article within a socio-cultural and dialogically framed approach to learning through design. The case presented below is not posed as a proof but an heuristic to highlight an argument and provide means to abstract later models

\section{An Illustrative Case}

\subsection{The Design Context and Design Brief}

Drawing on the research mentioned in the previous section, we now examine an illustrative and heuristic example drawn from a product design $2^{\text {nd }}$ year course at the Institute for 
Design at AHO. A group of 21 students, divided into teams of three, was given the task to develop a new mouth retractor (used to hold the mouth open when installing dental braces; see Figure 2). According to the design brief, the product should be injection moulded in plastic. This product was chosen as a way to foster students' design competencies concerning new design methods, injection moulding and computer aided design (CAD) abilities, and also to meet the needs of the dental industry to be more innovative and user-oriented. The project had a time frame of three weeks. Over the last 10 years we have run more than 30 projects like this and have developed an optimized approach for tailoring our teaching input and ensuring a measure of optimized learning.

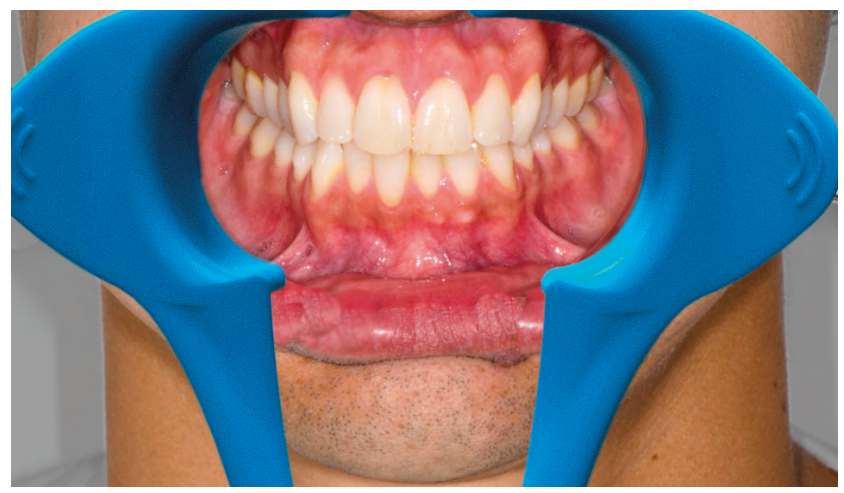

Figure 2. Mouth retractor, the final design solution. (Design and picture by Aleksandra Wojcik, Ole Birger Neergård, Aleksandra Fischer).

\subsection{Unpacking the Design and Learning Brief}

First, the task was handed out with initial information about the nature of the product to be developed and the niche of the market to be met. In the following next three days students drew on material and experience and developed insights from the Web, friends with braces, dentists and from the company that produces today's version of retractors. In this period, the teacher's role was mainly that of facilitating, giving advice and being present for queries and suggestions. As a result, the actual learning process was totally driven by the students' own engagement with the task and the dialogical approach to learning was dependent on their own taking of initiative in a supportive design developmental environment.

\subsection{Applying 'Designerly' Techniques}

Given that this is part of a pedagogy of developing mastery in learning, and not merely the mirroring activities of an apprenticeship model[39], no new skills nor an extensive body knowledge were explicitly presented or taught by the design educators. At this stage in their education, students have developed their tacit knowledge; they employ a range of designerly techniques such as analysing, drawing, making models, and using methods that have been learned previously. Figure 3 shows an example of drawings made during this process. In this process, students also gained explicit knowledge through user testing and physical measuring. Foremost, however, they evolved their skills in making hand drawings, and as a result increased their tacit knowledge. The company who introduced the task, found these drawings very useful and stated they were a different way of working towards new solutions.

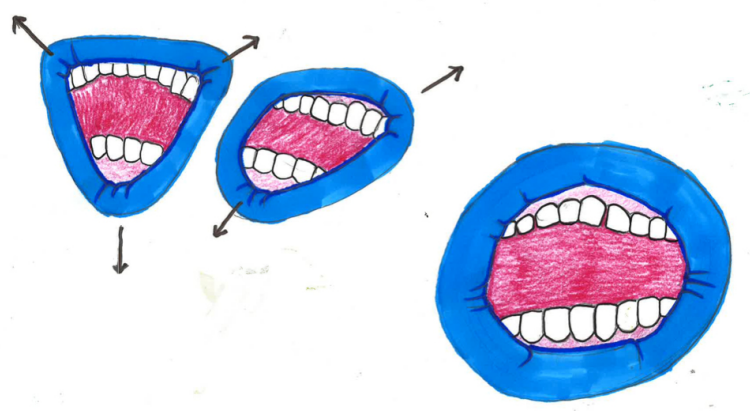

Figure 3. Drawings depicting the challenges. Hundreds of drawings like these were produced, first to analyze the situation, then to generate new concepts and to compare them. (Picture by Aleksandra Wojcik, Ole Birger Neergård, Aleksandra Fischer).

\subsection{Shaping Physical Manifestations}

After two to three days' work, previous acquired knowledge had a tendency to run short as a means to solving the given new task. At this point, students were motivated to identify and deploy new methods to be able to come up with solutions to the design need. Figure 4 shows a method of generating physical variations of a possible solution. The students found that doing physical iterations through prototyping gave them confidence in make choices, some students found this method especially gratifying.

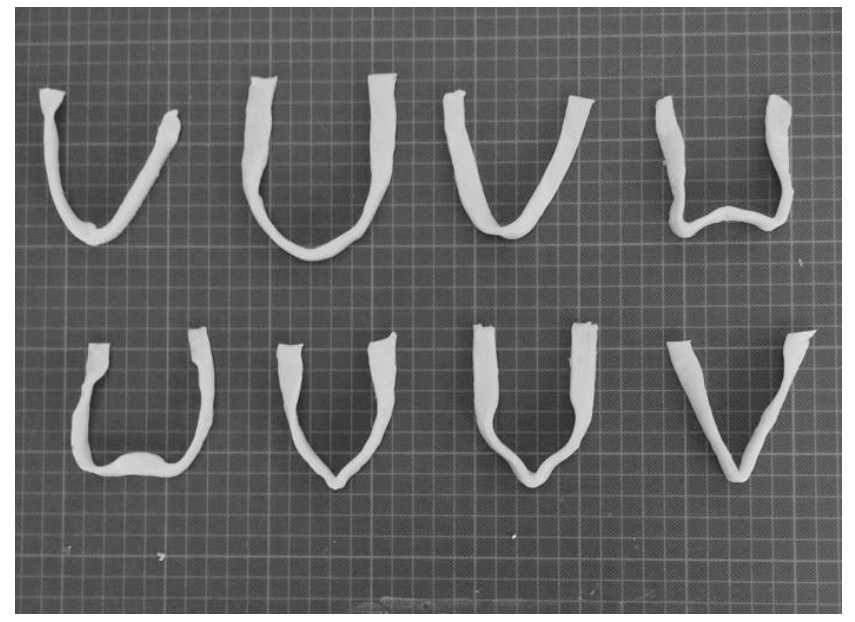

Figure 4. Physical variation of an intended design, picture and design Aleksandra Wojcik, Ole Birger Neergård, Aleksandra Fischer

The shaping of physical manifestations helped lead towards making a good decision, and rendering what could be 'fashioned'. This method also served as argumentation to 
the customer if they would wonder if something could have been done differently concerning the shape. In our experience, this is a convincing and very helpful developmental design learning method.

\subsection{Optional Solutions}

Then, after four days the students presented three suggestions for a solution. One of these was chosen following which they had two weeks to see this design selection through to 'completion' by making a working, producible retractor through using $3 \mathrm{D}$ printing. At this stage they were first given a lecture about injection moulding. At this point they had their design to cater for, with several challenges regarding producability and cost and the motivation to learn about this highly technical complex production method that was one of the main goal for this three-week project. (See Figure 5 for an example of an injection-moulding tool). Students said they now were able to abstract their design and could translate tooling issues by analysing a tool from a totally different project (Figure 5).

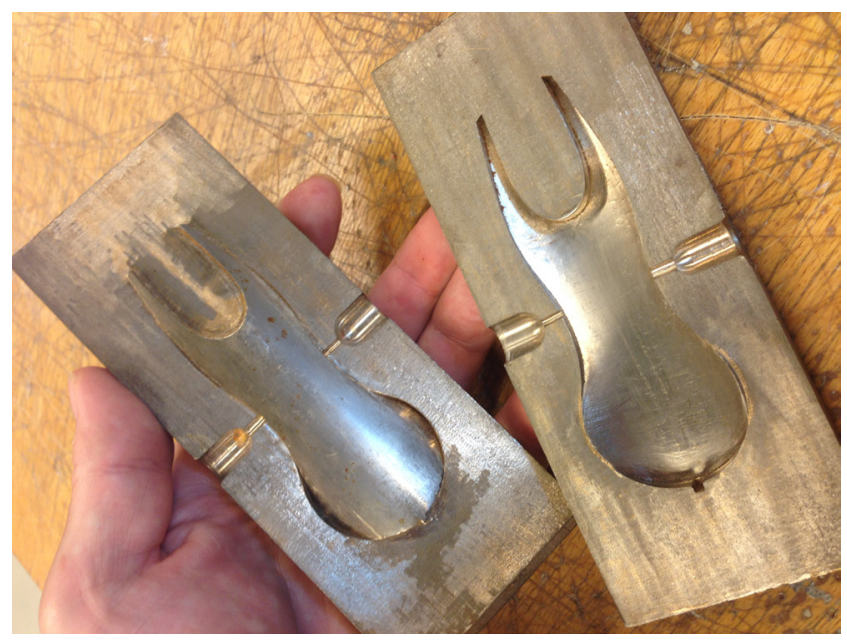

Figure 5. An example of an injection moulding tool, used in a lecture to explain how the process of this design technique works and what is needed to design products for injection molding. (Picture by Steinar Killi).

\subsection{Drawing on Digital Skills}

Next, when digitizing their design, the students drew on their basic skills in digitizing. However, they soon understood that these alone were insufficient to actually realise their intended design. Some students were inclined to tweak their design to be able to digitize it, but most of the students quickly looked for solutions elsewhere. The intended shape was quite organic and the digitizing program they were familiar with, SolidWorks, is not a good tool for working with such shapes. This now became a period of frustration: students spent hours attempting to create the design in the program (SolidWorks) that they already knew. Some students claimed that being introduced to a new digitizing program should have been done before the project started, however, the majority disagreed with this. The result of this was that either they succeeded or they became highly motivated to learn another CAD program more suited to solving their problem.

\subsection{Digital Multilteracies}

In this stage of the pedagogical trajectory, the students independent learning drove them to search for software, processes and means suited to the task. They did not simply stick to what did not function; they needed to actively and collaboratively look for alternate routes to achieving the task, thereby enacting the designerly actions required to approach a complex problem or an intricate design process. In a sense they became centred on tools, but at the same time connected to insights on their own learning at a meta level as part of their wider digital multiliteracies. Here discussion and dialogue between students formed a major part of the way this played out in the wider group. Several students said they felt this part of the project gave them the highest learning outcome.

\subsection{Specific Lectures during Open Window}

Parallel with all these student-driven initiatives to meet the demands of the brief and the emergent ones connected to their processes of creation, lectures were given on branding, production costs and the like. This was carried out at a time when the window of motivation was wide open. Interestingly, students were at this time able to handle multiple types of input; they chose and discarded relevant knowledge simultaneously when working. The interest to push limits, but still anchor these attempts based on their continuously acquired knowledge base were high.

\subsection{Pressure to Complete}

Towards the end of the project, during last two to three days, the window to learn anything was almost closed. All that is in focus at this point is finishing the task and delivering the result. At this point, all the students leaned heavily on previous projects and what they had already learned about how to finalise matters, make a presentation, complete a report etc. All students felt that presenting their result for an external company gave them an important incitement to work extra hard towards the end of the project. Again, this is course training of tacit skills and knowledge that should be transferable to other, future, and as yet unspecified, tasks. The students developed different ways of presentation techniques, extensive use of video filming, similar projects, use of humour, music etc. In doing presentations during their process and then at the end for their teachers and peers, new techniques emerged and evolved. For example, some students chose to wear the mouth retractor themselves during presentations, other chose to video film different users. 


\section{Discussion}

\subsection{Mapping a Motivation Cycle}

The different stages in a design-based project are usually grouped as five [40] or four elements [41], depending reasons for separation. If we follow Archibald[41], the four sequential stages of project development are: Conception, Definition, Execution and the Closeout. If we place these stages along a timeline and in the same graph incorporate the level of learning motivation, we may detect a window for learning and teaching.

We have conceptualized this at a more abstract level through what we term Mapping a Motivation Cycle. As can be seen in Figure 6, such a mapping, learning motivation is quantified as low, medium and high. Experience and refinement of this curve has been developed over 10 years and in more than 30 projects. It will of course differ in strength and position, but we now use it as a tool for planning project based inquiry. This applies not only to each project, but also to the design of whole semesters of study. In a wider evaluative sense, we have found that it an effective means to ensure that the decided learning outcomes are met. The Mapping a Motivation Cycle also offers a number of phases that may be fruitful to pursue for other areas of design inquiry where these phases are unpacked in terms of multiliteracy learning actions.

\subsection{Deconstructing Motivation and Design Learning}

The curve in this instance of the Mapping a Motivation Cycle (Figure 6) shows four distinct phases (I-IV), not necessarily aligned with the project phases (along the $\mathrm{x}$-axis). The first phase called Conception is during start up. Product design students are usually well motivated when starting up a new project and are eager to learn about the context and boundaries. However, this positive phase has a tendency to lose its power quite fast and a kind of first order fatigue[42] sets in. In this phase, the amount of information is sometimes overwhelming for students. According to the example with the mouth retractor, this happened when students discovered how many versions of this product already existed.

In the second phase labelled Definition, there is an imminent need to learn. This may vary between being skills, methods or facts. In the example above, students were introduced to new methods to handle all the knowledge that had been gathered. Through the Definition phase there is a slow decline in motivation followed by a more distinct dip downwards.

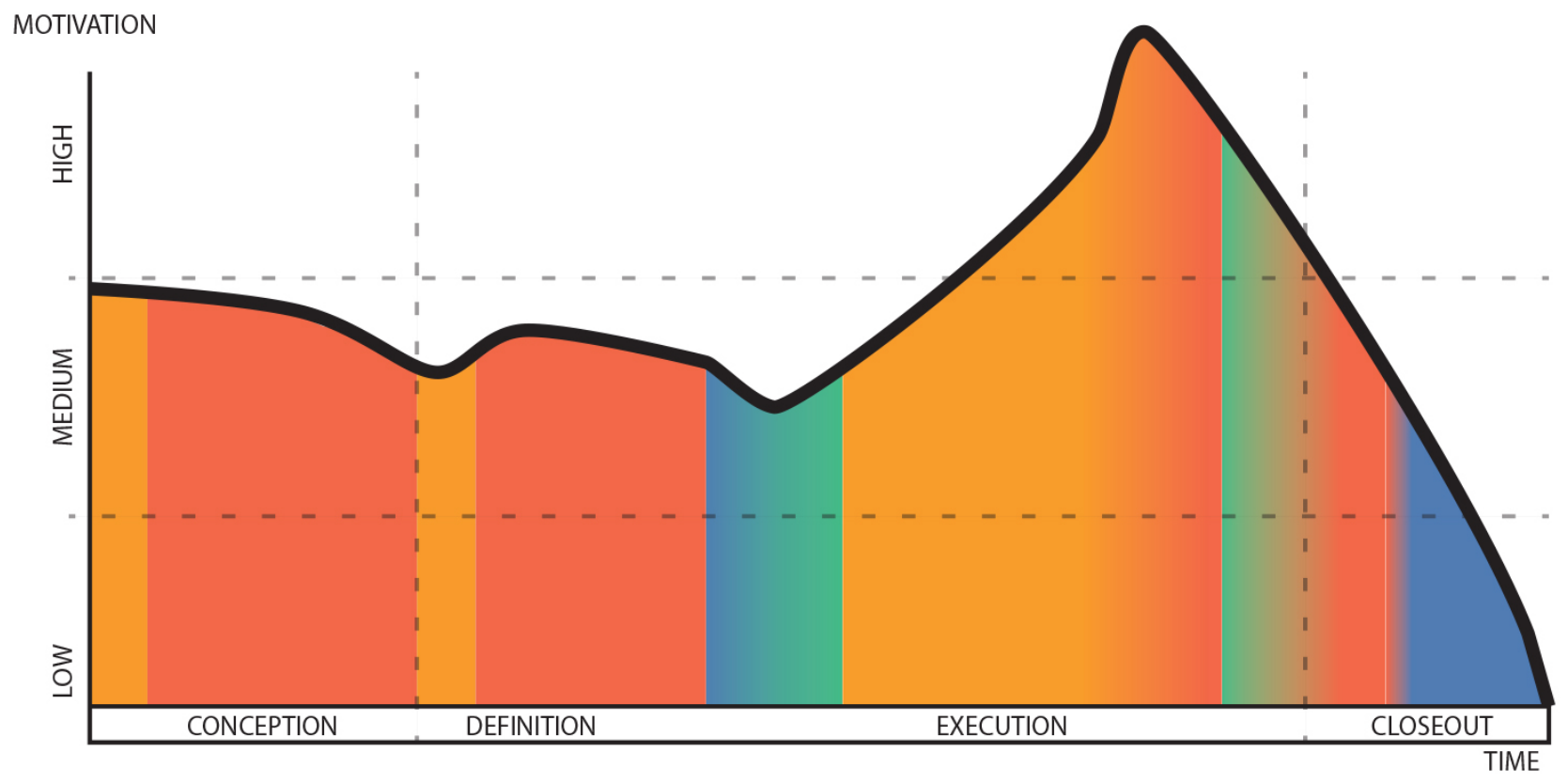

TYPE OF MOTIVATION

Figure 6. Motivation cycle through a design project. The main curve shows the overall learning motivation through the project, the colors depicts when the specific type of learning motivation will appear. Both resource use and other planning could benefit from this curve. The curve is not static, it will alter due to different influences; type and length of projects, type of students (advanced, beginners) and what kind of learning outcome we want to achieve. (Graph by Maria Karlsen, Steinar Killi \& Andrew Morrison). 
This happens in the beginning of the third or Execution phase. Here students start out depending on earlier knowledge/methods to carry out the task. Sometime into this third phase, there is a steep increase in learning motivation. This is the time students need to learn new skills, methods or when just facts peaking, very often leading to a breakthrough and an increased momentum in learning. In the example this occurred when the concept had to be realized, at the lowest cost possible. Students now really needed to know how injection moulding worked and more about the driving forces behind costs. At this point in the process needs are well known and understood; this is the best time for actual teaching.

In moving into the final and fourth phase, called Closeout, there is a strong decline in motivation. At this point, students seek to finalize their design work and see that through to full realization. Active teaching is now viewed as a disturbance.

It is important to understand that developing and increasing tacit knowledge goes on continuously through the project. However, it seems to have a stronger impact when conscious learning motivation is lower. In other words, as long as the skills and knowledge already acquired are sufficient, the motivation to learn new things is lower. At the same time, though, existing skills are honed and developed. In the example given, students continued sketching, building mockups and did tests, all things they had learned to do in previous projects.

\subsection{Just-in-time Teaching with Just-in-need Learning}

When looking at the curve (Figure 6) we see that all four types of motivation for learning are present. As previously stated, the different types of learning motivation should be handled differently by the teacher in order to enhance the outcome of the learning process. For instance, when intrinsic motivation to acquire tacit knowledge is high, the best thing a teacher can do is to allocate time and disturb students' own engagement as little as possible. When motivation shifts to extrinsic, but are nonetheless still tacit, a distinct clarity is necessary on the part of the teachers. This is evidenced in short response time to questions, limiting the scope of commentary, and an overall move to help maintain focus. When dealing with explicit knowledge, timing is even more important: when the intrinsic motivation to acquire explicit knowledge is high, we are in the sweet spot for teaching.

This is truly the time when the students have real Just-in-need to learn demand and opportunity. As teachers we should design projects to anticipate the different learning motivations and the need to act accordingly; this includes intense input of explicit knowledge when the time is optimal, and allocating time for building tacit knowledge.

\section{Conclusions}

\subsection{Towards Apposite Pedagogic Action}

The main goal in the article has been to contribute with the experiences made during the last 10 years, which has led to new, and more conscious, ways of designing courses in product design in higher education. Before starting a course there are specific learning goals; since at times during a course students have an enhanced motivation to learn, the course should be designed in a way that aligns the teaching input with this time period.

This may be elaborated a little further in what we see as a potentially fruitful concept for looking into the dynamics and positioning of such choice relating to Just-in-time and Just-in-need teaching and learning. The concept 'apposite pedagogic action' is proposed to refer to the situated, locative, temporal and content elements that together need to be factored into acts of exploratory and decisive making and appropriately timed and placed in relation to pedagogical decisions and related learning events. In our view, this concept sits well with others in the sociocultural perspective on dialogically framed learning. It would apply well to the interplay of materials, tools, technologies, mediational events and activities in the making of meaning. It would also entail the multiple and intersecting activities that characterize much of design thinking and practice based knowledge production.

It is our view that the approach discussed could be implemented within other educational programmes and specific briefs and design domains other than industrial or product design, for instance in primary school. As stated previously, learning and motivation are strongly connected. From a pedagogical view, it is just as important to know when as to know how to provide teaching input. A great lecture could indeed be fantastic if it's delivered appositely, that is at the appropriate time!

\section{Acknowledgements}

We acknowledge the participation of many students in courses at our institute over the years in making our learner centered pedagogies what they are today, that is hopefully ones richer in tacit and explicit knowledge, but also reflection and critical revision. Our thanks to the two reviewers and Ole Smørdal for critical comments.

\section{REFERENCES}

[1] Morrison A. Inside multimodal composition. 2010.

[2] Wertsch J. Mind as action. New York: Oxford University Press, 1998.

[3] Wertsch J. Voices of the mind: A Sociocultural approach to mediated action. Cambridge MA: Harvard University Press, 1991.

[4] Hmelo S, Cindy E. Problem-Based Learning: What and how do students learn? Educational Psychology Review 2004;16(3):31

[5] Vygotsky L. Thought and Language. Cambridge: The MIT press, 1962. 
[6] Vygotsky L. Mind in society. the development of higher psychological processes. Cambridge: Harvard University Press, 1978.

[7] Lave J, Wenger E. Situated learning: legitimate peripheral participation. Cambridge, England: Cambridge University Press, 1991.

[8] Brown J, Collins A, Duguid P. Situated Cognition and the culture of learning. Educational Researcher 1989;18(1):10

[9] Scardamalia M, Bereiter C. Knowledge building: Theory, pedagogy, and technology. In: Sawyer K, ed. Cambridge Handbook of the Learning Sciences. New York: Cambridge University Press, 2006:pp 97-118.

[10] Schön DA. The reflective practitioner: how professionals think in action. Aldershot: Arena, 1995.

[11] Kuhn S. The Software design studio: an exploration. IEEE Software 1998;15(2):7

[12] Nelson HG, Stolterman E. The design way: intentional change in an unpredictable world, foundations and fundamentals of design competence. Englewood Cliffs, NJ: Educational Technology Publications, 2003.

[13] Cross N. Designerly ways of knowing. London: Springer Science+Business Media, 2006.

[14] Lawson B. What designers know. Amsterdam: Elsevier, 2004.

[15] Dym CL, Agogino AM, Eris O, et al. Engineering Design Thinking, Teaching and Learning. Journal of Engineering Education 2005;94(1):18: pages 103-121

[16] Adderley K, Askurin C, Bradbury P, et al. Project methods in higher education. . London: Society for Research into Higher Education, 1975.

[17] Sahin M, Yorek N. A comparison of problem-based learning and traditional lecture, students' expectations and course grades in an introductory physics classroom. Scientific research and Essay 2009;4:10 : pages 753-763

[18] Daniel J. Making Sense of MOOCs: Musings in a Maze of Myth, Paradox and Possibility. Open Education researc 2013

[19] Kember D, Gow L. Orientations to Teaching and Their Effect on the Quality of Student Learning. The Journal of Higher Education 1994;65(1):17: pages 58-75

[20] Briggs KL, Wohlstetter P. Key Elements of a Successful School-Based Management Strategy. School Effectiveness and School Improvement 2003;14(3):22: pages 351-373

[21] Saeed S, Zyngier D. How Motivation Influences Student Engagement: A Qualitative Case Study. Journal Education and Learning 2012;1(2):16 doi: 10.5539/jel.v1n2p252[published Online First: Epub Date]: pages $252-268$

[22] McCombs B. Developing Responisble and Autonomous Learners: A Key to Motivating Students. Secondary Developing Responisble and Autonomous Learners: A Key to Motivating Students [Wb page] 2013.

[23] Barron BJS. Doing With Understanding: Lessons From Research on Problem- and Project Based Learning. The Journal of the learning sciences 1998;7(3\&4):40: pages 271-311

[24] Blumenfeld PC, Soloway E, Marx RW, et al. Motivating
Project-Based Learning: Sustaining the Doing, Supporting the Learning. Educational Psychologist 1991(26):30: pages 369-399

[25] Malone TW, Lepper MR. Making Learning Fun: A Taxonomy of Intrinsic Motivations for Learning. Aptitude, Learning, and Instruction 1987;3:30: pages 30-53

[26] Barr RB, Tagg J. From Teaching to Learning: A New Paradigm for Undergraduate Education. Change: The Journal for Higher Education 1995;27(6):14: pages 13-27

[27] Wood SL, Lynch Jr JG. Prior Knowledge and Complacency in New Product Learning. Journal of Consumer Research 2002;29(3):10: pages 416-426

[28] Polanyi M. The Tacit Dimension. New York: Anchor Books, 1967.

[29] Nightingale P. If Nelson and Winter are only half right about tacit knowledge, which half? ASearlean critique of "codification". Industrial and Corporate Change 2003;12(2):34: pages 149-186

[30] Ledford GE, Gerhart B, Fang M. Negative Effects of Extrinsic Rewards on Intrinsic Motivation: More Smoke than Fire. World at Work 2013(2):29

[31] Lemos M, Verissimo L. The Relationships between Intrinsic Motivation, Extrinsic Motivation, and Achievement. Along Elementary School. Procedia - Social and Behavioral Sciences 2014;112:8

[32] Tsoukas H. Do we really understand tacit knowledge? Oxford: Blackwell Publsihing Ltd, 2003.

[33] Jonas W. Design Research and its Meaning to the Methodological Development of the Discipline. Design research now, part 4 2007:187-206 doi: 10.1007/978-3-7643-8472-2 11 [published Online First: Epub Date]|.

[34] Sevaldson B. Discussions \& Movements in Design Research A systems approach to practice research in design. FORM Akademisk 2010;3(1):8-35

[35] Alvesson M, Sköldberg K. Reflexive methodology: new vistas for qualitative research London: Sage, 2000.

[36] Koskinen I, Zimmermann J, Binder Thomas, et al. Design research through practice: Morgan Kaufmann, 2011.

[37] Stringer E. Action research: A handbook for practitioners. Thousand Oaks: Sage, 1996.

[38] Denzin N, Lincoln Y, editors. The SAGE handbook of qualitative research 4ed. Los Angeles: SAGE, 2011.

[39] Rogoff B. Apprenticeship in thinking: Cognitive developments in social context. New York: Oxford University press, 1990.

[40] Cleland DI. Project Management: Strategic Design and Implementation. New York: McGraw \& Hill, 1999.

[41] Archibald R. State of the Art in Project Management in 2010. PMI Milwaukee/Southeast Wisconsin Chapter. Milwaukee, 2005.

[42] Lent RG. Overcoming Textbook Fatigue: 21st Century Tools to Revitalize Teaching and Learning. Alexandria, Virginia USA: ASCD, 2012. 